\title{
The Comparison of the Image Quality of Portable Miniature and Conventional Light Sources Used in Flexible Cystoscopy: An In Vitro Evaluation
}

\author{
(1) Uygar Miçooğulları, (1) Volkan Ülker \\ University of Health Sciences Turkiye, Izmir Tepecik Training and Research Hospital, Clinic of Urology, Izmir, Turkiye
}

\section{What's known on the subject? and What does the study add?}

In endourology, miniaturization and portability of endoscopic instruments are important for performing cystoscopy at bedside and office conditions. This study aimed to perform image quality and cost analysis of a portable light source in cystoscopy and compare its features with the conventional endoscopic light source. Our study revealed that portable halogen light sources provided comparable image quality to conventional xenon light sources during flexible cystoscopy. This study used the halogen portable light source that is cheaper than lightemitting diode portable ones, which is an additional advantage.

\section{Abstract}

Objective: Portability and miniaturization of endoscopic instruments are important in urological practice for flexible cystoscopy in bedside and office conditions. However, the adequacy of portable light sources is doubtful. Thus, this study aimed to compare the portable halogen and conventional light sources in terms of image quality and cost.

Materials and Methods: An in vitro model was designed using portable halogen and a conventional endoscopy light source. Two videos of simulated cystoscopy were recorded using the portable and another two using the conventional light source. These videos were rated in the following 5 areas: overall video quality, brightness, sharpness, contrast, and color. The imaging quality of the two light sources was compared. Additionally, the cost analysis was compared in both light sources.

Results: The image quality rating was performed by 83 evaluators. The overall video quality, brightness, sharpness, and contrast evaluation revealed a significant difference between the light sources in terms of brightness, and the score was higher in the conventional light source ( $\mathrm{p}<0.05)$. Color reproduction results were as follows: $68.67 \%$ great similarity, $27.71 \%$ little similarity, and $3.61 \%$ no similarity between the images produced using the two light sources. A portable light source was considered to be cost-effective.

Conclusion: The portable light source resulted in minimal degradation in image quality for flexible cystoscopy compared with the conventional endoscopy light source. This system can capture high-quality images with minimal equipment and is easy to set up. We believe that a portable halogen light source is sufficient to perform cystoscopic procedures in bedside and office conditions with limited cost. Further studies are needed to evaluate the efficacy of new cystoscopy systems that integrate mobile technology and new portable light sources.

Keywords: Image quality, flexible cystoscopy, portable light source

\section{Introduction}

Cystoscopy is one of the most frequently used procedures in daily clinical practice in urology. Indications of cystoscopy include facilitating the urethral catheter insertion, hematuria and intravesical pathology diagnosis, biopsy, foreign body removal, ureteral stent placement or removal, and infravesical obstruction or ureteral orifice evaluation $(1,2)$. Flexible scopes, compared to rigid ones, allow more comfortable endoscopy with minimal morbidity and have less postprocedural hematuria and analgesic need (3).

Correspondence: Uygar Miçooğulları MD, University of Health Sciences Turkiye, İzmir Tepecik Training and Research Hospital, Clinic of Urology, İzmir, Turkiye Phone: +90 5435888989 E-mail: uygarmico@hotmail.com ORCID-ID: orcid.org/0000-0003-4729-6104

Received: 20.04 .2021 Accepted: 17.05 .2021

Cite this article as: Miçooğulları U, Ülker V. The Comparison of the Image Quality of Portable Miniature and Conventional Light Sources Used in Flexible Cystoscopy: An In Vitro Evaluation. J Urol Surg, 2022;9(1):47-51.

๑Copyright 2022 by the Association of Urological Surgery / Journal of Urological Surgery published by Galenos Publishing House. 
Sometimes, performing bedside flexible cystoscopy, such as for critical patients in the intensive care unit (ICU) or in the emergency department (ED), might be necessary. A standard cystoscopy needs an endoscopy tower, which includes a light source and video unit. This transportation is generally timeconsuming and impractical. Additionally, having an extra endoscopy tower in the ICU and ED is not financially feasible. In such cases, performing cystoscopy with a portable light source would be very practical. Small portable endoscope light sources have gained popularity, especially in otolaryngology, and we believe that they can also be used as alternative light sources in urology (4). Miniaturized endoscope systems are ideally sized for portability, and when integrated with smartphone devices, these systems can become widely accessible and can reach a bigger population regardless of geographic and socioeconomic constraints (5). However, there might be a concern of whether the quality of the image generated with the smartphoneendoscope system with a portable light source is sufficient for cystoscopy since an insufficient light source may lead to suboptimal endoscopy, where small bladder tumors may be missed or urethral access cannot be gained. This in vitro study compared the image qualities of flexible cystoscopy videos using portable halogen and conventional xenon light sources and analyzed the cost-efficiency of using a portable light source.

\section{Materials and Methods}

This 2-part study was designed using a flexible fiberoptic cystoscope (CYF-5, Olympus Tokyo, Japan), portable halogen light source (MAJ-524, Olympus, Tokyo, Japan), and conventional xenon light source (CLV190, Olympus, Tokyo, Japan). The same high definition (HD) video system and camera head were used with both light sources (Evis Exera III CV-190 and CV-S190-XZE/Q, Olympus, Tokyo, Japan).

In the first part of the study, the color reproduction was evaluated using Gretag-Macbeth color checker (Color Checker Mini, $5.7 \times 8.25 \mathrm{~cm}$, X-Rite Inc. Grand Rapids, MI, USA). The test environment was prepared by a doctor and a technician. The flexible cystoscope visualized a Color Checker at an angle of 90 degrees and a distance of $2 \mathrm{~cm}$ (Figure 1). Gretag-Macbeth is a test pattern that is scientifically designed to help determine the true color balance or optical density of any color rendition system. It is an industry-standard that provides a non-subjective comparison with a test pattern of 24 scientifically prepared colored squares. Each color square represents a natural object that provides a qualitative-maintaining color reference to countable values (Figure 2a). Video-1 and video-2 were recorded with portable and conventional light sources, respectively. Observers graded the color representation from 0 to 2 ( 0 as no similarity; 1 as little similarity; and 2 as great similarities) between the images taken using two light sources (Figure $2 b$, $2 c)$.

In the second part of the study, the video image quality was compared in terms of the overall video quality, brightness, sharpness, and contrast. After obtaining written informed consent, video-3 and video-4 were recorded with the portable and conventional light sources, respectively, during urethrocystoscopy of the same patient. Both 15-sec-long videos included the view of verumontanum, ureteral orifices, and bladder wall. Then, two videos were rated by observers using a 5-point Likert scale, with 1 as unusable, 2 as very annoying, 3 as annoying, 4 as perceptible, but not annoying, and 5 as imperceptible images. The snap-shots of videos are shown in Figure 3. Eighty-three urologists and last-year residents of urology from 3 cities blindly evaluated 4 videos and rated them.

Cost analysis was made according to the retail prices provided by the authorized representative of Olympus in our country. For the analysis of the conventional system, the light source and the light cable were considered, excluding the endoscopy tray.

\section{Statistical Analysis}

The Statistical Package for the Social Sciences 22.0 (IBM, Chicago, IL, USA) version for Windows was used for statistical analysis. The Likert scale results from our crowd-sourced expert evaluators were summarized using descriptive statistics. First of all, the normality of the distribution of variables was evaluated

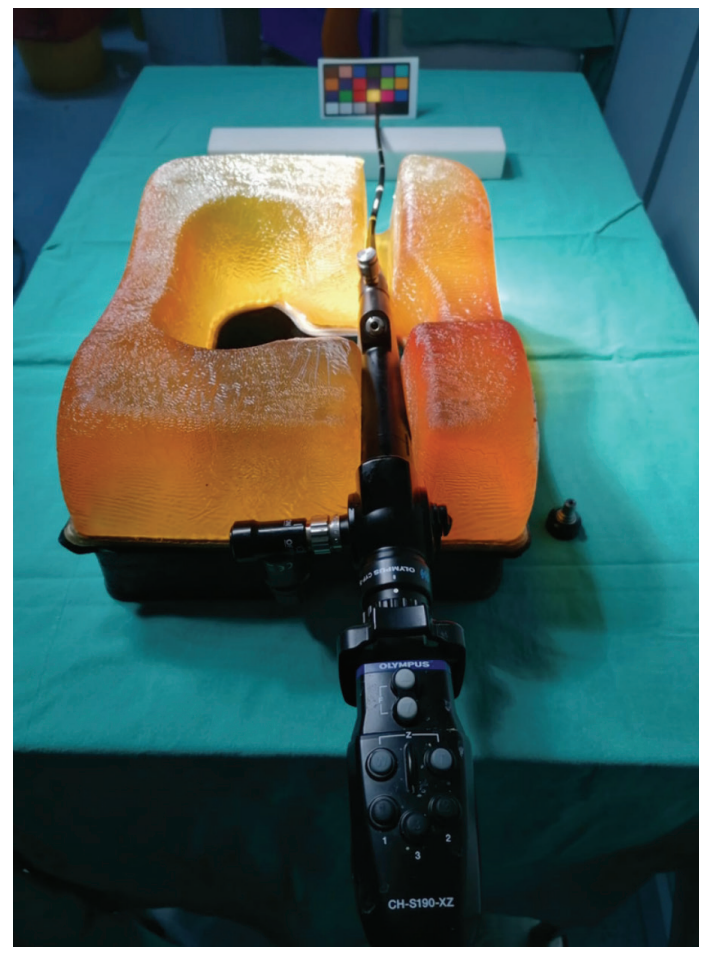

Figure 1. In vitro model for comparing different light sources with a GretagMacbeth Color Checker $7 \times 8.25 \mathrm{~cm}$ and an Olympus fiberoptic flexible cystoscope 
with three tests. The coefficient of variation (standard deviation Imean) was below 30\% in all groups. The evaluation of the Skewness-Kurtosis values revealed that the current values were between -2 and +2 in all groups. The variables fitting the normal distribution were evaluated with the Student t-test. A p-value of $<0.05$ was considered significant.

\section{Results}

Eighty-three expert evaluators completed the image quality ratings. The overall video quality, brightness, sharpness, and contrast evaluation revealed that the only statistical

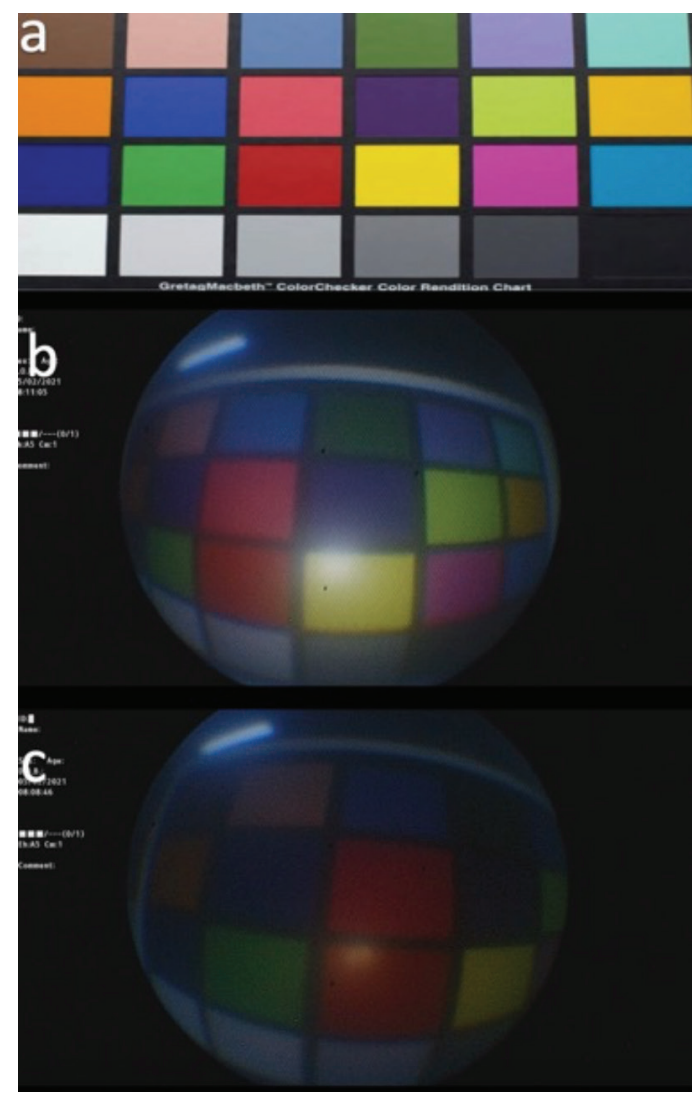

Figure 2A. Gretag-Macbeth X-rite Color Checker, $5.7 \times 8.25 \mathrm{~cm} \mathrm{B.} \mathrm{Screenshot}$ of the video taken with the conventional xenon light source. $\mathbf{C}$. Screenshot of the video taken with the portable halogen light source difference between light sources was seen in terms of brightness $(p<0.05)$ (Table 1$)$. The brightness score was significantly higher in the conventional light source group (Table 1). The experts' ratings of image quality from both light sources are schematized in Figure 4a. Based on the Color Checker results, 57 of the expert evaluators rated images generated using two light sources as having great similarity, 23 as little similarities, and 3 as no similarity (Figure $4 b$ ). The costs of portable halogen and conventional xenon light sources used in tests were $\$ 1,150$ and $\$ 15,000$, respectively. The cost analysis indicated that the price difference between portable halogen and conventional xenon light sources including light cable was $\$ 15,050$.

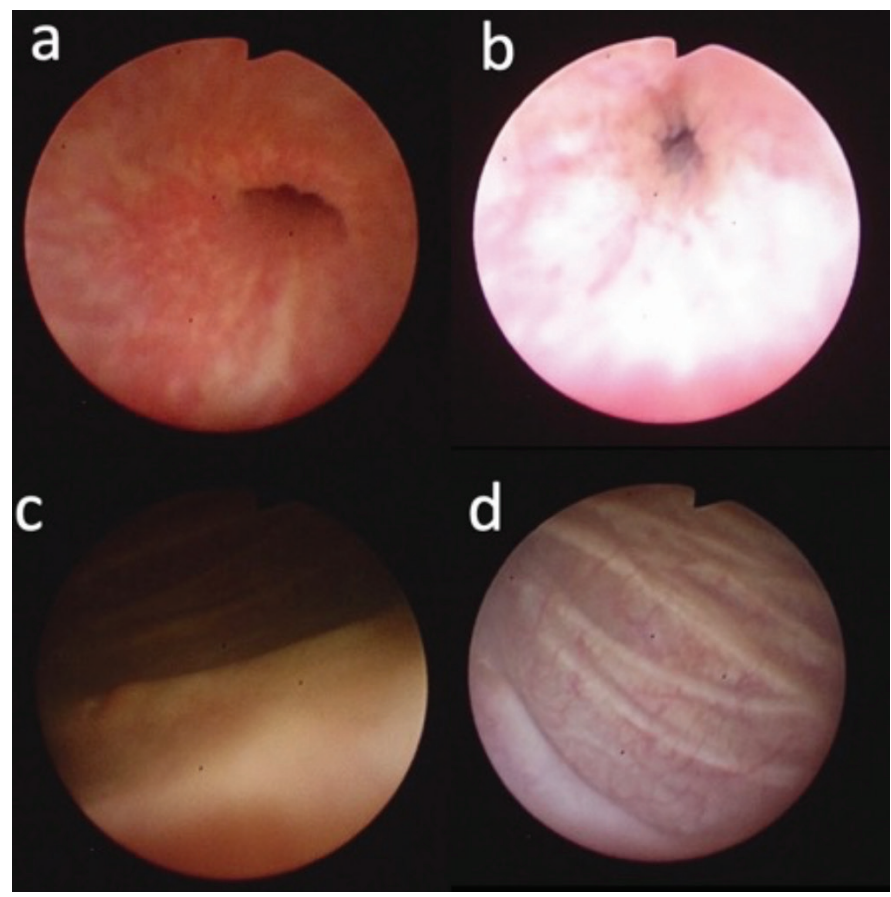

Figure 3A. Screenshot of the video of the urethra taken with the portable halogen light source, B. Screenshot of the video of the urethra taken with the conventional xenon light source, $\mathbf{C}$. Screenshot of the video of the bladder and right ureter orifice taken with the portable halogen light source, D. Screenshot of the video of the bladder and right ureter orifice taken with the conventional xenon light source

\begin{tabular}{|c|c|c|c|c|c|}
\hline Parameters & Group & $n$ & Mean & Standard deviation & $p$ \\
\hline Overall video quality & Conventional light source & 83 & 4.50 & 0.68 & 0.06 \\
\hline \multirow{2}{*}{ Brightness } & Conventional light source & 83 & 4.43 & 0.71 & \multirow{2}{*}{0.00} \\
\hline & Portable light source & 83 & 2.89 & 0.92 & \\
\hline Sharpness & Portable light source & 83 & 4.21 & 0.68 & 0.059 \\
\hline \multirow{2}{*}{ Contrast } & Conventional light source & 83 & 4.20 & 0.83 & \multirow{2}{*}{0.078} \\
\hline & Portable light source & 83 & 3.97 & 0.82 & \\
\hline
\end{tabular}




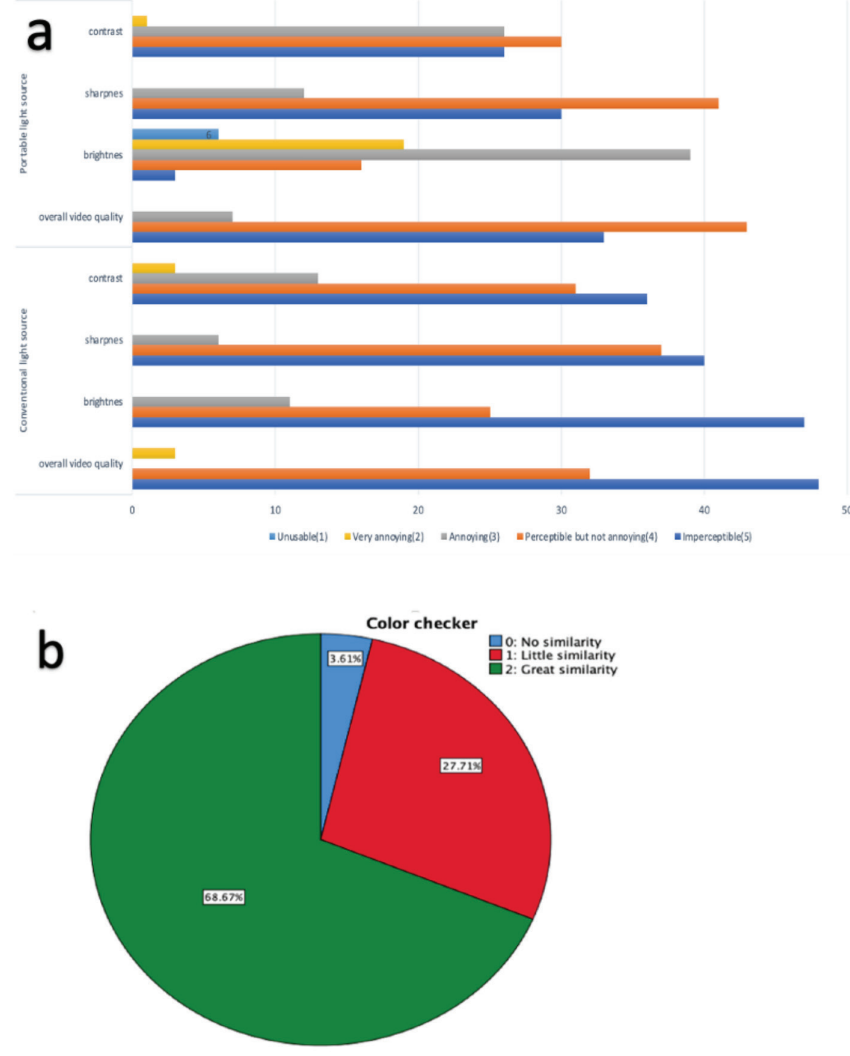

Figure 4A. Expert evaluators' ratings of image quality of both light sources, B. Ratings of color similarity with the color checker

\section{Discussion}

Cystoscopy has become an indispensable tool for urologists since it was first developed by Nitze in 1879 (6). Bedside cystoscopy provides great advantages and convenience when treating patients with limited mobility and those who stay in the ICUs $(1,7)$. Additionally, conventional cystoscopy can provide highquality images; however, bringing an endoscopy tower to the patient's room can be challenging (7). Since Nitze first developed the cystoscope, constant innovation and development have been done that led to the instruments urologists use today. A flexible cystoscope is the product of these developments $(8,9)$. Digital flexible scopes require their integrated video and light source systems, while fiberoptic scopes can use a portable light source. Newer digital flexible cystoscopes are increasingly used in developed countries; however, fiberoptic flexible cystoscopes are still extensively used worldwide because of their significantly lower cost (10).

One of the most common indications for bedside flexible cystoscopy is the placement of a difficult urethral catheter (11). Flexible cystoscopy with a portable light source allows the urologist to perform fast and practical procedures at the bedside, ED, or the office. The main concern in cystoscopy with a portable light source is image quality, while the second concern is cost-effectiveness. This study assessed the quality of images made with a high-fidelity cystourethroscopy simulator using a portable light source and compared them to the ones made using a conventional light source.

Studies have evaluated the feasibility of integrating mobile technology into cystoscopy systems and clinical results have been presented $(4,5,7,12,13)$. Chatzipapas et al. (12) compared a portable light-emitting diode (LED) light source with a conventional light source in rigid cystoscopy and revealed no difference in the image quality and diagnostic adequacy between the two setups. However, they did not conduct any statistical analysis in their study. Tse et al. (5) used a three-dimensional printed attachment that connected a smartphone with a portable LED light source. They concluded that portable LED light source was comparable to the conventional light source. Another study by Dutta et al. (13) revealed similar results with a portable LED light source and smartphone screen. Butler et al. (4) compared smartphone-generated light with portable light sources used in bedside laryngoscopy and reported similar results with both. Our study also revealed that a portable light source is comparable to a conventional xenon light source in terms of overall video quality, sharpness, and contrast. Only the brightness score of the conventional light source was significantly higher. Additionally, 
any significant difference was not found between the two light sources in the color reproduction component. Our results support the previous studies. The halogen portable light source we used in this study is cheaper than LED portable ones, which is an additional advantage.

Another issue that needed to be evaluated was the cost of the light source. Previous studies reported significant cost differences. One study reported that the total cost of the endoscope system with a portable LED light source coupled with a smartphone was $\$ 750$, while a conventional video cystoscope with a standard HD camera and xenon source costs $\$ 45,000$ (5). Similarly, Chatzipapas et al. (12) revealed a \$46,401 cost difference between the video system they tested. Our study revealed a \$15,050 cost difference, which was significant between the two systems in the test platform. Considering the cheapest conventional light source of the same brand that can be used in ED or office, the cost together with the light cable is $\$ 4285$. This is still $\$ 3,135$ more expensive than a portable halogen light source. Additionally, the halogen portable light source was $\$ 200$ cheaper than the portable LED light source. Its low cost may allow different departments to have their flexible cystoscope with portable light sources instead of sharing one conventional video endoscopy tower.

\section{Study Limitations}

Our study has some limitations. Mainly, only the light source component of the cystoscopy system was evaluated and a conventional HD camera system and monitor were used for recording index videos. Secondly, portable LED light source might have produced better results than the halogen light source, but we chose to evaluate halogen light source because it's cheaper than LED and has comparable results to conventional xenon light source. Our study results will help further develop a portable light source and smartphone combination that is flexible cystoscopy for ED or office use.

\section{Conclusion}

Our study showed that portable halogen light sources provided comparable image quality to conventional xenon light sources during flexible cystoscopy. The brightness parameter was better with a conventional light source; however, the difference was not statistically significant. The portable halogen light source is a reasonable alternative to a conventional xenon light source for bedside and office use. Portable light source's opensource design, low cost, and adaptability to smartphones may encourage its widespread and rapid adoption in clinical practice, especially in low-resource centers.

\section{Ethics}

Ethics Committee Approval: It is not necessary.

Informed Consent: Informed consent was obtained.

Peer-review: Externally and internally peer-reviewed.

\section{Authorship Contributions}

Surgical and Medical Practices: V.Ü., Concept: U.M., V.Ü., Design: U.M., V.Ü., Data Collection or Processing: U.M., V.Ü., Analysis or Interpretation: U.M., Literature Search: U.M., V.Ü., Writing: U.M., v.Ü.

Conflict of Interest: No conflict of interest was declared by the authors.

Financial Disclosure: The authors declare that they have no relevant financial.

\section{References}

1. Clayman RV, Kramolowsky EV. Bedside flexible cystoscopy: an approach to the critically ill patient. J Urol 1986;135:1179-1180.

2. Beaghler M, Grasso M 3rd, Loisides P. Inability to pass a urethral catheter: the bedside role of the flexible cystoscope. Urology 1994;44:268-270.

3. Erdem MR, Topaloğlu K, Yücebaş ÖE, Şengör F, Aslan AR, Tosun Ç, Ramazanoğlu MA, Duvar S. Better Comfort for Both Patient and Doctor: Prospective Randomized Study about Flexible and Rigid Cystoscopy. J Urol Surg 2015;2:65-68.

4. Butler JJ, White SF, Myint CWM, Groves MW. The Feasibility of Utilizing Smartphone Flashlights as an Alternative Endoscopic Light Source in Emergency Situations. Ear Nose Throat J 2021;100:NP1-NP6.

5. Tse C, Patel RM, Yoon R, Okhunov Z, Landman J, Clayman RV. The Endockscope Using Next Generation Smartphones: "A Global Opportunity". J Endourol 2018:32:765-770.

6. Nitze M. Eineneue Beleuchtungs und Untersuchungs method fur Harnrohre, Harnblase, und Rektum. Wiener Med Wochen 1879;24:649.

7. Guo Y, Kshatri K, Matsumoto ED, Kapoor A. Expert and Crowdsourced Evaluation of Image Quality From a Novel Endoscopy Phone Light Adapter. Urology 2020;146:54-58.

8. Engelsgjerd JS, Deibert CM. Cystoscopy. 2020 Apr 24. In: StatPearls [Internet]. Treasure Island (FL): StatPearls Publishing; 2021 Jan-. PMID: 29630232.

9. Samplaski MK, Jones JS. Two centuries of cystoscopy: the development of imaging, instrumentation and synergistic technologies. BJU Int 2009;103:154-158.

10. Quayle SS, Ames CD, Lieber D, Yan Y, Landman J. Comparison of optical resolution with digital and standard fiberoptic cystoscopes in an in vitro model. Urology 2005;66:489-493.

11. Kadi N, Menezes P. ABC of flexible cystoscopy for junior trainee and general practitioner. Int J Gen Med 2011;4:593-596.

12. Chatzipapas I, Kathopoulis N, Protopapas A, Kyritsis N, Vlachos D E, Loutradis D. Mobile Cystoscope. HJOG 2017;16:23-28.

13. Dutta R, Yoon R, Patel RM, Spradling K, Okhunov Z, Sohn W, Lee HJ, Landman J, Clayman RV. Clinical Comparison of Conventional and Mobile Endockscope Videocystoscopy Using an Air or Fluid Medium. J Endourol 2017:31:593-597. 